\title{
PENYULUHAN PERAN KADER DALAM MENINGKATKAN LITERASI KESEHATAN MASYARAKAT DI DESA CIMANGGU, BANDUNG BARAT
}

\author{
Ditha Prasanti * \\ Universitas Padjadjaran \\ Ikhsan Fuady \\ Universitas Padjadjaran
}

\begin{abstract}
CULTIVATION OF CADRE ROLE IN IMPROVING COMMUNITY HEALTH LITERATION IN CIMANGGU VILLAGE OF BANDUNG BARAT DISTRICT. Community Service Activities has the objective to produce outcomes, namely: 1) Providing concrete knowledge and insight on the counseling of the role of cadres in improving public health literacy in the village Cimanggu, Bandung Barat District; 2) Provide an understanding of the importance of the role of cadres in improving the public health literacy in Cimanggu village, District of Bandung Barat. The method of PKM implementation conducted in this training activity is method of lecture method; Group discussion methods; and video playback methods. The conclusions of this PKM activity are: (1) As a benchmark for Kader members in Cimanggu village to be able to increase public health literacy for better village development; (2) Awakening PKM participants on the importance of the role of Cadres in improving public health literacy; (3) Increasing awareness of PKM participants on the importance of increasing public health literacy in order to support the successful development of Cimanggu village.
\end{abstract}

KEYWORDS: Counseling, Health Cadres, Literacy.

* Corresponding Author: Program Studi Ilmu Komunikasi Fakultas Ilmu Komunikasi Universitas Padjadjaran; Jl. Raya Bandung Sumedang KM. 21, Hegarmanah, Jatinangor, Kabupaten Sumedang, Jawa Barat 45363; Email: dithaprasanti@gmail.com

Article History: Received: 27-8-2017; Revised: 09-11-2017; Accepted: 30-11-2017

Permalink: http://ppm.ejournal.id/index.php/pengabdian/article/view/21

How to cite (APA): Prasanti, D., \& Fuady, I. (2017). Penyuluhan peran kader dalam meningkatkan literasi kesehatan masyarakat di Desa Cimanggu, Bandung Barat. Jurnal Pengabdian Pada Masyarakat, 2(2), 83-92.

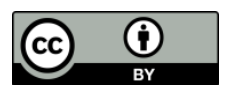

This is an open access article distributed under the terms of the Creative Commons Attribution 4.0 International License, which permits unrestricted use, distribution, and reproduction in any medium, provided the original work is properly cited. @ 2017, Ditha Prasanti, Ikhsan Fuady.

\section{PENDAHULUAN}

Kesehatan menjadi hal penting yang perlu diperhatikan dalam kehidupan manusia. Tidak hanya dalam keluarga, kesehatan juga menjadi faktor penunjang keberhasilan pembangunan di sebuah daerah. Dalam rangka mewujudkan peningkatan kualitas kesehatan ini, beberapa daerah juga membentuk tim kader kesehatan untuk membantu pelaksanaan program kesehatan di daerah tertentu. Jadi, sudah selayaknya, tim kader juga memiliki literasi kesehatan masyarakat yang baik. 
Kader kesehatan telah menyita perhatian dalam beberapa tahun terakhir ini, karena banyak program kesehatan dunia menekankan potensi kader kesehatan untuk meningkatkan derajat kesehatan pada masyarakat. Brazil adalah salah satu contoh terkini yang masyarakatnya dilibatkan dalam sistem kesehatan nasional. Dari hasil analisis awal ada hal yang menarik dalam peran yang dirasakan oleh kader kesehatan, peran kader kesehatan bermain di masyarakat, peran kader kesehatan masyarakat dapat bervariasi secara dinamis tergantung pada masalah yang timbul di masyarakat setiap hari, dan tugas ini dilakukan hampir setiap saat di setiap tempat (Kahn, 2008).

Sejarah munculnya kader kesehatan masyarakat pada mulanya di Amerika Serikat pada tahun 1960, karena menanggapi masalah kemiskinan yang ada. Proyek ini didanai swasta dengan menghasilkan bukti yang signifikan bahwa manfaat kader kesehatan masyarakat dalam mempromosikan kesehatan dan meningkatkan akses ke layanan kesehatan masyarakat sangat berhasil (Massachusetts, 2009).

Literasi kesehatan masyarakat seharusnya menjadi titik tolak pembangunan kesehatan di Indonesia. Dengan berpijak pada konsep bahwa literasi kesehatan masyarakat tidak hanya ditentukan oleh masyarakat itu sendiri, namun juga dipengaruhi dan dibentuk oleh petugas kesehatan, institusi kesehatan melalui pelayanan informasi dan pemerintah melalui kebijakan-kebijakan yang dilahirkannya, maka sudah selayaknya masyarakat dibantu melalui edukasi untuk dapat meningkatkan kemampuan literasi kesehatannya, misalnya melalui peran dari tim kader kesehatan yang berada di daerah tersebut.

Menurut Zarcadoolas et al (2006), rendahnya tingkat literasi kesehatan berkontribusi terhadap beberapa masalah kesehatan seperti, penggunaan obat obatan yang tidak semestinya, pelayanan kesehatan yang tidak mencukupi, menejemen yang buruk untuk kondisi kondisi kronis, kondisi yang kritis, kondisi kesehatan yang kurang baik, rendahnya keyakinan dan penghargaan diri, terkurasnya keuangan individu dan masyarakat dan diskriminasi secara sosial.

Berdasarkan latar belakang masalah di atas, penulis melakukan kegiatan Pengabdian Kepada Masyarakat (PKM) tentang Penyuluhan Peran Kader dalam Meningkatkan Literasi Kesehatan Masyarakat di Desa Cimanggu, Kab. Bandung Barat. Penulis melihat antusiasme tim kader di Desa Cimanggu. Oleh karena itu, melalui kegiatan PKM ini, penulis ingin memberikan penyuluhan tentang pentingnya peran kader dalam upaya meningkatkan literasi kesehatan masyarakat di Desa Cimanggu. 


\section{Peran Kader}

Pengertian kader kesehatan atau Posyandu, menurut Depkes RI (2003) adalah anggota masyarakat yang dipilih dari dan oleh masyarakat, mau dan mampu bekerja bersama dalam berbagai kegiatan kemasyarakatan secara sukarela.

Sementara menurut WHO (1998) merupakan laki-laki atau wanita yang dipilih oleh masyarakat dan dilatih untuk menangani, masalah-masalah kesehatan perorangan maupun yang amat dekat dengan tempat-tempat pemberian pelayanan kesehatan. Menurut Depkes RI (2003), terdapat beberapa syarat menjadi Kader, antara lain:

1) Dipilih dari dan oleh masyarakat setempat.

2) Bersedia dan mampu bekerja bersama masyarakat secara sukarela.

3) Bisa membaca dan menulis huruf latin.

4) Sabar dan memahami usia lanjut.

Kader kesehatan masyarakat sebagai garis depan bagi masyarakat yang anggotanya terpercaya dan atau memiliki pemahaman yang lebih mengenai kesehatan, karena kader kesehatan masyarakat merupakan perantara atau penghubung antara pelayanan kesehatan dengan masyarakat dalam memfasilitasi dan meningkatkan kualitas kesehatan di masyarakat. (Massachusetts Department of Public Health, 2009).

Kader kesehatan juga mampu menyediakan berbagai layanan dan memainkan sejumlah peran. Mereka membantu individu dan masyarakat dalam mengadopsi perilaku gaya hidup sehat. Mereka mampu melaksanakan programprogram yang mempromosikan, memelihara dan meningkatkan kesehatan individu dan masyarakat. Secara khusus, kader kesehatan masyarakat memberikan informasi tentang sumber daya yang tersedia menawarkan dukungan sosial dan konseling informal serta membantu mengkoordinasi perawatan di sektor kesehatan (Martinez, 2010).

\section{Literasi Kesehatan Masyarakat}

Literasi kesehatan umumnya dikaitkan dengan kemampuan membaca dan menulis seseorang. Hal ini sesuai dengan definisi literasi kesehatan yang dinyatakan oleh The American Medical Association yang mewakili model biomedis sebagai kemampuan membaca dan memahami resep obat, kartu berobat dan bentuk materi lainnya yang berhubungan dengan peran dirinya sebagai pasien.

Sedangkan WHO yang mengarah pada model biopsikososial mendefinisikan literasi kesehatan sebagai keterampilan kognisi dan sosial yang menentukan 
motivasi dan kemampuan individu untuk mengakses, memahami dan menggunakan informasi sebagai cara untuk meningkatkan dan menjaga kesehatannya (Berry, 2006, p. 62).

Selanjutnya The National Library of Medicine's (NLM) dan Institute of Medicine (IOM) mendefinisikan literasi kesehatan "the degree to which an individuals have the capacity to obtain, process and understand basic health information and services needed to make appropriate health decisions" (Kindig, Panzer, \& Nielsen-Bohlman, 2004).

Pengetahuan dan konsep budaya yang melingkupi konsep literasi kesehatan selama ini diartikan sebagai kemampuan seseorang dalam memahami makna kesehatan, makna sakit, risiko dan keuntungannya. Namun belakang ini, konsep di atas juga meliputi peran penyelenggara kesehatan dalam berkomunikasi efektif dengan pasien untuk mengajak berpartisipasi menuju gaya hidup sehat melalui patient-centered communication (Levinson, Lesser, \& Epstein, 2010).

Literasi bahasa lisan yang harus dimiliki oleh tim kader kesehatan berkaitan dengan kemampuan mendengarkan dan berbicara. Masyarakat dan penyelenggara kesehatan harus bekerjasama dalam proses komunikasi yang intens sehingga dapat mendeskripsikan diagnosis dan informasi kesehatan lainnya dengan akurat.

Dengan demikian, literasi kesehatan bergantung pada karakteristik dari kedua belah pihak dalam sistem pelayanan kesehatan. Pengukuran literasi kesehatan yang hanya berdasarkan kemampuan membaca dan menulis dari masyarakat menjadi kurang tepat, karena literasi kesehatan juga dipengaruhi oleh kesulitan memahami pesan media cetak karena penyampaiannya yang terlalu kompleks. Demikian pula halnya dengan informasi yang disampaikan secara lisan oleh petugas kesehatan yang sulit dipahami.

Lebih jauh lagi, literasi kesehatan menurut Baker (2006) juga dipengaruhi oleh budaya dan norma yang berlaku dalam masyarakat yang membuat literasi kesehatan sulit untuk berubah. Dari perspektif ini, literasi kesehatan adalah keadaan dinamis individu yang dipengaruhi oleh lingkungan dimana individu itu berada dalam konteks yang berkaitan dengan informasi kesehatan yang pada gilirannya akan menentukan tingkat kesehatannya.

\section{Tujuan dan Manfaat PKM}

Kegiatan Pengabdian Kepada Masyarakat yang dilakukan oleh tim akademisi Program Studi Ilmu Komunikasi Universitas Padjadjaran (Unpad) memiliki target sebagai berikut: 
Pertama, masyarakat di Desa Cimanggu Kabupaten Bandung Barat menyadari pentingnya memiliki kemampuan dan pemahaman tentang pentingnya peran kader dalam meningkatkan literasi kesehatan masyarakat.

Kedua, masyarakat di Desa Cimanggu Kabupaten Bandung Barat memahami peran dan posisi kader kesehatan yang turut menunjang keberhasilan pembangunan kesehatan bagi masyarakat di Desa Cimanggu.

Ketiga, peserta penyuluhan memiliki kesadaran .sebagai tim kader dalam meningkatkan literasi kesehatan masyarakat di Desa Cimanggu.

\section{METODE PELAKSANAAN}

Kegiatan PKM yang berjudul penyuluhan peran kader dalam meningkatkan literasi kesehatan masyarakat ini, dengan mempertimbangkan materi penyuluhan, masyarakat sebagai audiens, masalah yang berkembang dan lingkungan yang mendukung, dalam pelaksanaannya akan menggunakan beberapa metode berikut:

Metode ceramah dan pendampingan, dengan memberikan wawasan umum kepada masyarakat mengenai pentingnya peran dan posisi kader kesehatan dalam meningkatkan literasi kesehatan masyarakat di desa Cimanggu, Kab. Bandung Barat.

Metode diskusi kelompok/simulasi, kami bermitra dengan pihak Kepala Desa dan koordinator tim kader atau layanan terkait, dengan memberikan kesempatan kepada peserta penyuluhan untuk menyampaikan pertanyaan seputar materi yang belum dipahaminya, lalu simulasi mengenai peningkatan literasi kesehatan masyarakat melalui diskusi kelompok.

Metode pemutaran video, kegiatan ini memberikan sesi khusus pemutaran video dokumentasi tentang pentingnya peran kader dalam meningkatkan literasi kesehatan masyarakat di Desa Cimanggu, Kab. Bandung Barat.

\section{HASIL DAN PEMBAHASAN}

\section{Hasil yang Dicapai}

Dalam kegiatan PKM ini, penulis melihat adanya partisipasi aktif peserta penyuluhan selama mengikuti kegiatan, dari awal sampai akhir. Hal inipun terus berlanjut melalui koordinasi penulis dengan pihak desa yang selalu memberikan kabar tentang berbagai kegiatan yang dilakukan tim kader kesehatan desa 
Penyuluhan Peran Kader Dalam Meningkatkan Literasi Kesehatan Masyarakat

di Desa Cimanggu, Bandung Barat

Cimanggu dalam membantu pelaksanaan program kesehatan pemerintah di desa Cimanggu.

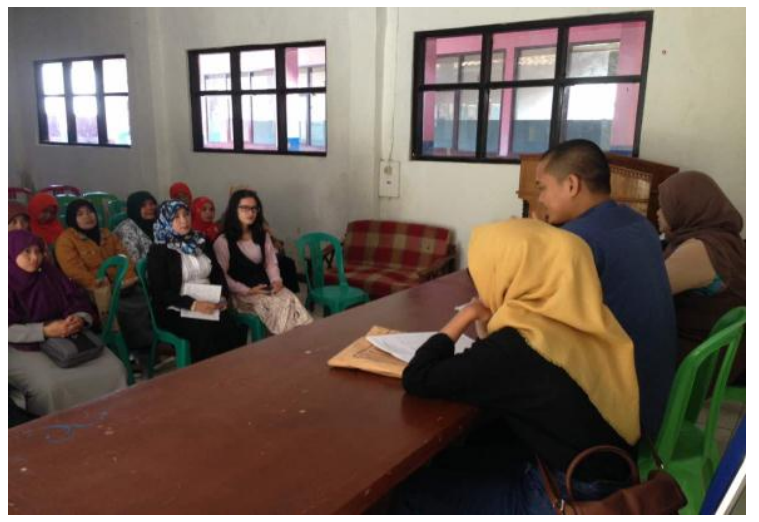

Gambar 1. Acara Pembukaan Kegiatan Penyuluhan oleh Tim Pengabdian Kepada Masyarakat (PKM) dan Kepala Desa beserta Staf

\section{Pemaparan Materi Pelatihan}

Ketika penulis menyampaikan materi mengenai literasi kesehatan masyarakat yang harus dimiliki oleh tim kader, para peserta mulai aktif bertanya dan menyampaikan pendapatnya tentang materi ini. Ada juga peserta yang menceritakan pengalamannya sebagai kader, merasa tergugah melalui penyuluhan ini bahwa ternyata kader kesehatan harus memiliki literasi kesehatan masyarakat yang baik dan benar.

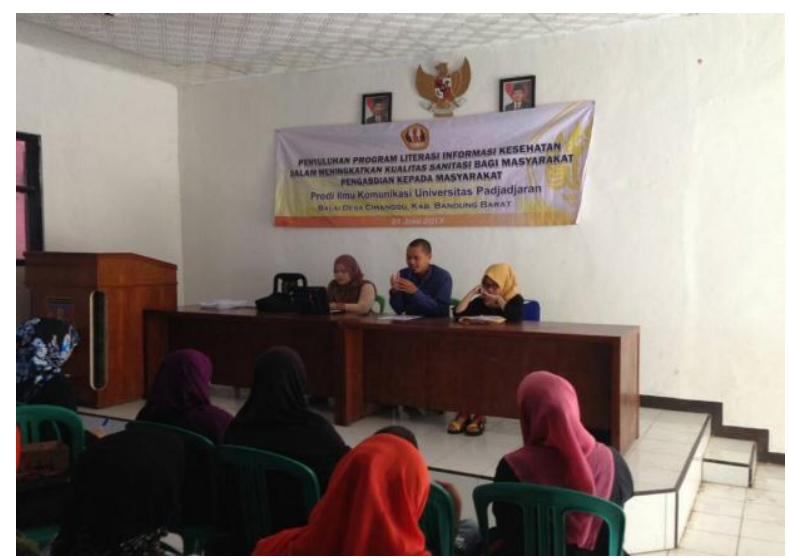

Gambar 2. Pemaparan Materi Penyuluhan tentang Peran Kader dalam Meningkatkan Literasi Kesehatan

Dalam sesi ceramah, penulis juga menyampaikan bahwa melalui peran kader kesehatan secara optimal diharapkan dapat meningkatkan derajat kesehatan masyarakat di wilayahnya. Hal ini juga akan terwujud jika para kader tersebut 
memiliki literasi kesehatan masyarakat yang baik dan benar. Inilah salah satu tujuan penyuluhan ini dilakukan, mengajak kader berpartisipasi aktif agar melek literasi kesehatan masyarakat.

Menurut Iin Rosita (2012), peran kader kesehatan adalah: 1) Terselenggaranya upaya promotif dan preventif terhadap masalah-masalah kesehatan oleh masyarakat sendiri; 2) Terdeteksinya masalah-masalah kesehatan secara dini yang ada di wilayah dengan adanya kader yang berilmu pengetahuan dan aktif; 3) Masyarakat mampu mengambil inisiatif untuk menyelesaikan masalah-masalah kesehatan diwilayahnya secara mandiri; 4) Memudahkan koordinasi antara petugas kesehatan dengan masyarakat (kader) untuk melaksanakan upaya-upaya kesehatan masyarakat.

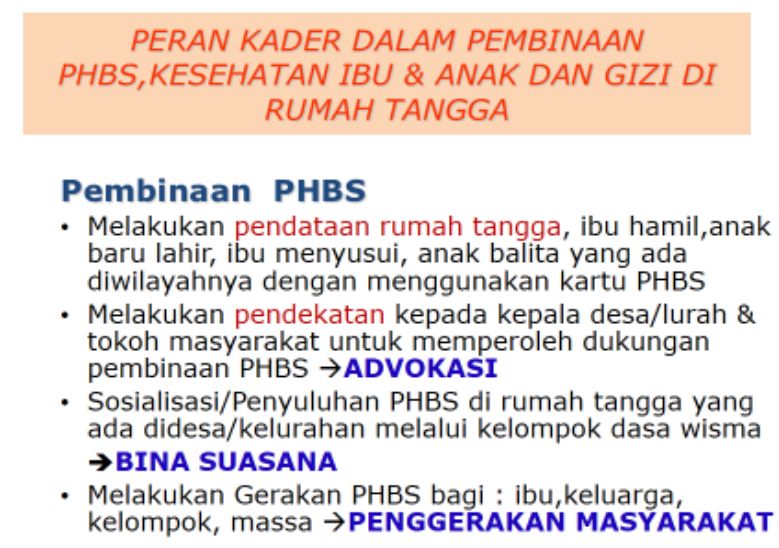

\section{Gambar 3. Materi Penyuluhan tentang Pentingnya Peran Kader dalam Meningkatkan Literasi Kesehatan Masyarakat}

Dalam sesi diskusi kelompok, penulis juga memberikan gambaran awal tentang peran kader kesehatan yang sangat penting dalam menunjang keberhasilan pembangunan di desa tersebut. Hal ini ditunjukkan dengan pembagian kelompok dalam kader kesehatan itu sendiri, agar fokus dalam membantu pelaksanaan program kesehatan yang bermacam-macam.

Rosita (2012) membagi kader kesehatan dalam beberapa kelompok, misalnya:

1) Kader Posyandu Balita. Kader yang bertugas di pos pelayanan terpadu (posyandu) dengan kegiatan rutin setiap bulannya melakukan pendaftaran, pencatatan, penimbangan bayi dan balita. 
2) Kader Posyandu Lansia. Kader yang bertugas di posyandu lanjut usia (lansia) dengan kegiatan rutin setiap bulannya membantu petugas kesehatan saat pemeriksaan kesehatan pasien lansia.

3) Kader Gizi. Kader yang bertugas membantu petugas puskesmas melakukan pendataan, penimbangan bayi dan balita yang mengalami gangguan gizi (malnutrisi).

4) Kader Kesehatan Ibu dan Anak (KIA). Kader yang bertugas membantu bidan puskesmas melakukan pendataan, pemeriksaan ibu hami dan anak-anak yang mengalami gangguan kesehatan (penyakit).

5) Kader Keluarga Berencana (KB). Kader yang bertugas membantu petugas KB melakukan pendataan, pelaksanaan pelayanan KB kepada pasangan usia subur di lingkungan tempat tinggalnya.

6) Kader Juru Pengamatan Jentik (Jumantik). Kader yang bertugas membantu petugas puskesmas melakukan pendataan dan pemeriksaan jentik nyamuk di rumah penduduk sekitar wilayah kerja puskesmas.

7) Kader Upaya Kesehatan Kerja (UKK). Kader yang membantu petugas puskesmas melakukan pendataan dan pemeriksaan kesehatan tenaga kerja di lingkungan pos tempat kerjanya.

8) Kader Promosi Kesehatan (Promkes) atau kader PHBS. Kader yang bertugas membantu petugas puskesmas melakukan penyuluhan kesehatan secara perorangan maupun dalam kelompok masyarakat.

9) Kader Upaya Kesehatan Sekolah (UKS). Kader yang bertugas membantu petugas puskesmas melakukan penjaringan dan pemeriksaan kesehatan anakanak usia sekolah pada pos pelayanan UKS.

Gambaran di atas menegaskan bahwa peran kader memegang posisi penting, karena sebagai penghubung antara pemerintah dan masyarakat tentang berbagai program kesehatan yang ada. Oleh karena itu, sudah selayaknya kader kesehatan dapat meningkatkan literasi kesehatan masyarakat agar pelaksanaan program pun menjadi lebih optimal.

\section{SIMPULAN}

Kegiatan PKM ini memberi tolak ukur seberapa jauh tim kader memahami peran dan posisi keberadaannya sebagai kader dalam meningkatkan literasi 
kesehatan masyarakat, demi menunjang keberhasilan pembangunan kesehatan di Desa Cimanggu.

Kegiatan PKM yang berkelanjutan diperlukan agar para peserta juga semakin termotivasi untuk meningkatkan literasi kesehatan masyarakat yang harus dimilikinya.

Dalam rangka mengoptimalkan peran kader kesehatan, sebaiknya hal ini juga didukung aktif oleh kesadaran dan kemauan tim kader serta dukungan dari pihak desa dan pemerintah, melalui berbagai macam pelatihan untuk meningkatkan kemampuan tim kader tersebut, misalnya dengan keikutsertaan dalam kegiatan PKM ini.

\section{REFERENSI}

Berry, D. (2006). Health communication: Theory and practice. UK: McGraw-Hill Education.

Baker, D. W. (2006). The meaning and the measure of health literacy. Journal of General Internal Medicine, 21(8), 878-883.

Depkes RI. (2003). Modul pelatihan bagi tenaga promosi kesehatan di puskesmas. Jakarta: Depkes RI.

Hernandez, L. M. (Ed.). (2009). Health literacy, eHealth, and communication: putting the consumer first: workshop summary. Washington DC: Institute of Medicine.

Kahn, R. G. (2008). The Role of Community Health Workers in Northeast Brazil. Stanford Undergraduate Research Journal Spring, 7, 52-55.

Kindig, D. A., Panzer, A. M., \& Nielsen-Bohlman, L. (Eds.). (2004). Health literacy: A prescription to end confusion. Washington DC: National Academies Press.

Levinson, W., Lesser, C. S., \& Epstein, R. M. (2010). Developing physician communication skills for patient-centered care. Health Affairs, 29(7), 13101318.

Martinez-Pons, M. (2002). A social cognitive view of parental influences on student academic self-regulation. Journal of Theory Into Practice, 41(2), 126-131. 
Massachusetts Department of Public Health Bureau of Family Health and Nutrition. (2008). Breastfeeding initiation and support. Retrieved August 20, 2017, from website http://www.mass.gov/Eeohhs2/docs/dph/com_health/nutrition/breastfeeding _guidelines.pdf.

Rosita, I. (2012). Peran kader kesehatan menuju Indonesia sehat 2015. Retrieved August 20, 2017, from website https://iinrosita.wordpress.com/2012/01/14/peran-kader-kesehatan.

Whoqol Group. (1998). Development of the World Health Organization WHOQOL-BREF quality of life assessment. Psychological Medicine, 28(3), 551-558.

Zarcadoolas, C., Pleasant, A., \& Greer, D. S. (2006). Advancing health literacy: A framework for understanding and action. CA: John Wiley \& Sons.

\section{Ucapan Terimakasih}

Artikel ini merupakan karya ilmiah yang ditulis berdasarkan hasil kegiatan Pengabdian Kepada Masyarakat (PKM) Fakultas Ilmu Komunikasi Universitas Padjadjaran, yang telah dilakukan di balai desa Cimanggu, Kab. Bandung Barat.

Oleh karena itu, penulis ingin mengucapkan terimakasih atas izin dan dukungannya kepada semua pihak: Prof. Dr. med. Tri Hanggono Achmad, dr., sebagai Rektor Universitas Padjadjaran; Rizky Abdullah, S.Si., Apt., Ph.D, sebagai Direktur DRPMI Universitas Padjadjaran; Dr. Dadang Rahmat Hidayat, S.Sos, S.H., M.Si, sebagai Dekan Fakultas Ilmu Komunikasi Universitas Padjadjaran; Dr. Purwanti Hadisiwi, sebagai Ketua Program Studi Ilmu Komunikasi; atas dukungan dan motivasinya kepada tim PKM, serta pihak/aparatur desa Cimanggu, Kab. Bandung Barat. 